\title{
Weight management in primary care: how can it be made more effective?
}

\author{
Alan Maryon-Davis \\ Southwark Primary Care Trust, Mabel Goldwin House, 49 Grange Walk, London SE1 3DY, UK and Guy's, King's and \\ St Thomas' School of Medicine, King's College London, Capital House, 42 Weston Street, London SE1 3QD, UK
}

\begin{abstract}
Obesity is often difficult to tackle in primary care. Pressure of time in the consultation, a lack of appropriately-trained primary care staff, a shortage of community dietitians or nutritionists, the potentially enormous caseload, language or cultural barriers and the sheer intractability of patients' eating habits, exercise behaviour and their clinical condition, all conspire to make general practitioners, other team members and often the patients themselves lose heart and stop even trying. However, there are ways of overcoming these difficulties. Examples of changes that evidence suggests are able to support and enhance basic one-to-one interventions in general practice include: improved clinical guidelines; better training of primary care staff; atrisk patient registers; smarter database search tools; new quality incentives; closer working with dietitians, counsellors and pharmacists; more hospital outreach clinics; designated general practitioner specialists and practice clustering; expanded exercise referral schemes and links with leisure providers; subsidised referral to commercial slimming groups; better use of patient groups and voluntary and community workers. The present paper describes a proposed 'tripletier' pathway for weight management incorporating most of the elements mentioned earlier. With a more joined-up and creative approach to the development and organisation of primary care, more comprehensive training and workforce planning, and better integration with social care, voluntary groups and the commercial sector, weight management in general practice has the potential to be much more effective.
\end{abstract}

Obesity: Weight management: Primary care

Obesity is now recognised as a major public health problem in the UK (Chief Medical Officer, 2003), posing a threat second only to smoking (Wanless, 2004). In England $22 \%$ of men (aged $\geq 16$ years) and $23 \%$ of women were obese (BMI $\geq 30 \mathrm{~kg} / \mathrm{m}^{2}$ ) in 2002 and the prevalence is increasing steadily (Joint Health Surveys Unit, 2003).

A recent study of deaths by cause has estimated that the UK has the highest percentage of deaths (8.7) attributable to excess weight in Europe (Banegas et al. 2003). The ill health linked to obesity is considerable. In the USA evidence suggests that it has already overtaken smoking as a cause of chronic ill health (Sturm \& Wells, 2001). Table 1 shows the relative risk of various diseases in obese $v$. non-obese individuals. For example, obese women are approximately thirteen times more likely to develop type 2 diabetes than non-obese women. The economic costs associated with obesity in England alone have recently been estimated as approximately $£ 3.5 \times 10^{9}$ each year (House of Commons Health Committee, 2004). If the costs of overweight (BMI 25-29 kg/m ${ }^{2}$ ) are included, this estimate would double (House of Commons Health Committee, 2004).

A weight loss of $5-10 \%$ body weight in obese individuals is associated with important health benefits, particularly in a reduction in blood pressure and a reduced risk of developing type 2 diabetes and CHD (Scottish Intercollegiate Guidelines Network, 1996). Recent reviews have shown that a low-energy dietary intake (with or without anti-obesity medication) together with increased physical activity and behavioural or psychological support can achieve beneficial amounts of weight loss, at least in the short term; maintenance of weight loss beyond the first year being more difficult (Centre for Reviews and Dissemination, 1997; National Heart, Lung, and Blood Institute, 1998; Mulvihill \& Quigley, 2003). 
Table 1. Relative risk of various diseases in obese $v$. non-obese individuals (National Audit Office, 2001)

\begin{tabular}{lcc}
\hline & \multicolumn{2}{c}{ Relative risk } \\
\cline { 2 - 3 } & Women & Men \\
\hline Type 2 diabetes & $12 \cdot 7$ & $5 \cdot 2$ \\
Hypertension & $4 \cdot 2$ & $2 \cdot 6$ \\
Heart attack & $3 \cdot 2$ & $1 \cdot 5$ \\
Colon cancer & $2 \cdot 7$ & $3 \cdot 0$ \\
Angina & $1 \cdot 8$ & $1 \cdot 8$ \\
Stroke & $1 \cdot 3$ & $1 \cdot 3$ \\
\hline
\end{tabular}

In relation to reduction in co-morbidities, the Diabetes Prevention Program in the USA (Diabetes Prevention Program Research Group, 2002) has recently shown that a $7 \%$ decrease in initial weight reduces the risk of developing type 2 diabetes by $58 \%$ in individuals with impaired glucose tolerance.

\section{The three 'E's model}

Any attempt at lifestyle modification must be seen in the context of today's 'obesogenic environment' (Swinburn et al. 1999). Cultural, social and economic influences on food choice and physical activity may be more powerful than therapeutic approaches. The present paper proposes a simple holistic theoretical model (Fig. 1) for considering ways to change health behaviour.

In this model 'encouragement' refers to simple exhortations to persuade individuals to change their lifestyle, e.g. to eat lower-energy foods, to take more exercise. This approach would include encouragement in clinical situations as well as the simple persuasive messages of most media campaigns. 'Empowerment' refers to the process of providing knowledge and skills, including life skills, to help an individual make healthful changes (i.e. an educational approach) that might include an awareness of basic nutritional principles, food-shopping skills, cooking skills, building confidence and self-esteem etc. Encouragement can only be effective in a context of empowerment. 'Environment' refers to the totality of the cultural, social, physical and economic environments required to facilitate improvements in lifestyle factors such as diet and physical activity, i.e. to make the healthier choices the easier choices. Encouragement and empowerment together can achieve little without a conducive total environment.

\section{Potential role of primary care}

Primary care provides a potentially ideal setting for weight-management interventions for adults. About $75 \%$ of the population see their general practitioner in the course of 1 year, and about $90 \%$ in 5 years (House of Commons Health Committee, 2004). Contact rates with community pharmacists are even higher. Primary care practitioners, particularly general practitioners, practice nurses, health visitors, community nurses, community dietitians and community pharmacists, are potentially well placed to detect and manage obesity in high-risk patients.

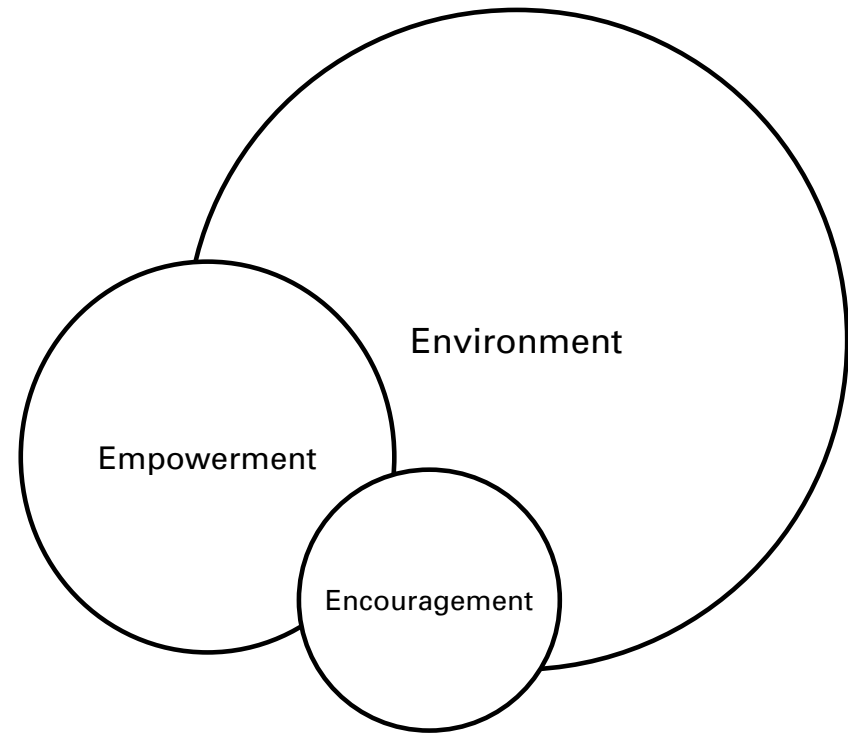

Fig. 1. The three 'E's model for lifestyle change. (Adapted from Maryon-Davis, 2003.)

The challenge is to make therapeutic weight management in everyday primary care practicable, effective and sustainable.

The present paper will consider evidence supporting various primary care-based approaches relating to weight management of obese adults only; children are covered elsewhere (see Wardle, 2005).

In terms of the three 'E's model lifestyle interventions to control obesity in the primary care setting are mainly concerned with individual encouragement and empowerment (the technique of motivational interviewing, for example, includes both elements), but should also attempt to create a less-obesogenic environment, particularly through the wider influence of the primary care organisation and the local strategic partnership.

\section{Main policy drivers}

The well-established links between obesity and chronic diseases such as type 2 diabetes and CHD make it a risk factor that cannot be ignored. In England and Wales weight management is specifically accorded targets and milestones in the National Service Framework for Coronary Heart Disease (Department of Health, 2000) and the delivery strategy for the Diabetes National Service Framework (Department of Health, 2003a). Similar directives exist for other parts of the UK. It also features prominently in the English Government's Public Health White Paper (Department of Health, 2004b).

\section{Clinical guidelines}

Clear unambiguous guidelines have been published outlining clinical pathways and therapeutic interventions at stated thresholds (Scottish Intercollegiate Guidelines Network, 1996; National Heart, Lung, and Blood Institute, 1998). Similar guidelines have been produced for Canada (Douketis et al. 1999). All these guidelines prioritise 
patients with co-morbidities such as diabetes, hypertension or heart disease for whom obesity is particularly problematical.

\section{Dietetic support}

A major review of forty-eight randomised controlled trials by the US National, Heart, Lung, and Blood Institute (1998) has found that low-energy diets achieve weight losses averaging 6-8\% and that maintaining weight loss is easier with continuous low-energy diets than with intermittent very-low-energy diets. The report's recommendations are:

low-energy diets are recommended for weight loss in overweight and obese individuals;

reducing fat as part of a low-energy diets is a practical way to reduce energy;

reducing fat alone without reducing energy is not sufficient for weight loss;

a diet that is individually planned to help create a deficit of $2 \cdot 1-4 \cdot 2 \mathrm{MJ}(500-1000 \mathrm{kcal}) / \mathrm{d}$ should be an integral part of any programme aimed at achieving a weight loss of $0 \cdot 5-1 \mathrm{~kg} /$ week.

A more recent systematic review has looked at the evidence relating to dietary interventions in the treatment of obese adults (Mulvihill \& Quigley, 2003). The main findings are that diets combining low fat and energy restriction and low-fat diets alone ( $\leq 30 \%$ total daily energy derived from fat) are effective at treating obesity and overweight in adults. However, there is conflicting evidence on their relative effectiveness.

\section{Increasing physical activity}

The effectiveness of different ways of encouraging increased physical activity in the management of overweight and obesity has been reviewed in a recent report from the Chief Medical Officer of England (Chief Medical Officer, 2004). In brief, its main conclusions are:

physical activity is an important element of weight management;

the greater the amount of activity, the more weight is lost;

physical activity is particularly useful for maintaining weight loss;

brief activity bouts of approximately $10 \mathrm{~min}$ are just as effective as the same total in longer bouts and improve adherence and sustainability.

The recommendation for maintenance of weight loss is a total of 60-90 min moderately-vigorous activity daily (in several shorter bouts if preferred). Any activity, however short, burns up energy. A more active lifestyle could be just as effective as structured exercise sessions.

Gains in activity levels and physical fitness in adults have been reported in trials of exercise advice in primary care in the UK, Australia and the USA (Stevens et al. 1998; Halbert et al. 2000; Activity Counseling Trial Research Group, 2001). The UK study, based on two general practices in West London, showed an increase in habitual physical activity in 45-74-year-olds at 8 months after being invited to a consultation with an exercise development officer and offered a personalised 10-week programme to increase their level of regular physical activity (Stevens et al. 1998).

A recently-published study has gone a stage further and shown sustainable health benefits from a primary carebased physical activity intervention in a diverse population aged 40-79 years (Elley et al. 2003). This cluster randomised controlled trial involved motivational advice on home-based physical activity (indoors or walking) from the general practitioner or practice nurse plus telephone support by leisure-centre staff. The trial showed that prompting the usual general practitioner for brief advice, coupled with ongoing telephone support, can change an individual's physical activity behaviour and improve self-rated general health and vitality for $\geq 1$ year.

A recent review (Hillsdon et al. 2004) of systematic reviews and meta-analyses of evidence concerning the effectiveness of physical activity interventions in healthcare settings has concluded:

brief advice from a doctor based in primary care, supported by written material, is likely to be effective in producing a modest short-term effect on physical activity;

referral to an exercise specialist based in the community can lead to longer-term changes in physical activity;

interventions using motivational approaches are associated with longer-term adherence;

interventions promoting changes to more active living (e.g. walking) that are not facility dependent are associated with longer-term adherence.

These principles are incorporated into most of the exercise referral schemes now operating throughout the country.

\section{Behavioural therapy}

The Health Development Agency review (Mulvihill \& Quigley, 2003) has found good evidence for the effectiveness of behavioural-support techniques. A combination of behavioural-therapy techniques in conjunction with other weight-loss approaches is effective for the treatment of adult obesity and overweight over a 1-year period. The following approaches have been found to be most effective: continued therapist contact and relapse prevention training; continued therapist contact by telephone and mail. Motivational interviewing is a relatively new technique that is proving valuable in helping individuals adopt and maintain changes in lifestyle (Rollnick et al. 1999).

\section{Drug treatment}

The National Institute for Clinical Excellence has published guidance supporting the use of the obesity drugs orlistat (National Institute for Clinical Excellence, 2001a) and sibutramine (National Institute for Clinical Excellence, $2001 b$ ) in certain limited circumstances, and stipulates that they must be supported by dietary and lifestyle changes. 
A recent review of fourteen double-blind randomised controlled trials of $\geq 1$-year duration of drug treatment (orlistat, eleven trials; sibutramine, three trials) for obese patients has found that these drugs could achieve weight losses of 3-4\% more than diet alone or a placebo (Padwal et al. 2003). Most of the trial patients were women (70-80\%), average age 50 years, and altogether $12 \%$ of patients on orlistat, and $15 \%$ of patients on sibutramine achieved a $10 \%$ weight loss. Side effects were reported to be a problem with both orlistat and sibutramine; drop-out rates averaged $33 \%$ for the former and $43 \%$ for the latter. The review concludes that drug treatment of obesity can achieve a useful additional weight loss for a few patients, but substantial adverse effects for many patients.

\section{Hospital-based treatment}

Although primary care provides the best starting point for treating individuals with weight problems, more specialist care may be needed for patients with severe or complex problems related to their obesity, and those with lifethreatening morbid obesity. In-patient treatment, notably surgery, can achieve substantial and sustained weight loss in selected patients (National Audit Office, 2001).

\section{Organisational aspects}

A Cochrane review (Harvey et al. 2004), conducted in 2001, has looked at trials of interventions aimed at improving the management of obesity and overweight by primary care practitioners and at different organisational models for delivering weight-management care in general practice. It was found that there are few solid ideas for improving obesity management in primary care, although reminder systems, brief training interventions, shared care and dietitian-led treatments are all thought worthy of further investigation. The review also concludes that further research is needed to identify cost-effective strategies for improving the management of obesity.

The Health Development Agency's systematic review (Mulvihill \& Quigley, 2003) has found evidence to support efforts to improve the role of health professionals in the management of obesity and overweight, in particular by:

reminders to general practitioners to prescribe diets; a brief educational training intervention on obesity management delivered by behavioural psychologists to general practitioners;

encouraging shared care between general practitioners and a hospital service;

use of in-patient obesity treatment services;

training provision for both health professionals and leaders of self-help weight-loss clinics.

\section{Training}

Clearly, improving the training of front-line primary care staff, in terms of nutrition, physical activity and helping patients to change lifestyles is an important prerequisite. However, evidence to date of the effectiveness of such training packages has been mixed (Harvey et al. 1999; Moore et al. 2003). For example, Moore et al. (2003) have found that a brief training programme for primary care practitioners improves their knowledge concerning lifestyles and obesity, and increases their recording of height, target weight and current weight, but does not result in improved weight loss in obese patients. Moreover, use of the brief weight-management protocol is low. The investigators have concluded that a more in-depth training programme might be more successful but is unlikely to be of general use, and other strategies to manage obesity in primary care urgently need to be considered and evaluated.

\section{Patchy provision}

In the UK a major report (National Audit Office, 2001) has concluded that the approach to weight management in the National Health Service is patchy and that work is needed to develop effective strategies to treat obesity at policy and provider level. This view has been endorsed more recently by the report of the House of Commons Health Committee (2004) who received evidence that the typical primary care intervention was ad hoc, half-hearted, desultory, poorly supported and short-term. Community dietetics services, exercise referral services and community-based physical activity coordinators were reported as being in particularly short supply. Further evidence to support the conclusion of patchy provision has come from a Dr Foster (2003) survey, which has shown that over half the primary care organisations in the UK do not have organised weight-management clinics within their local areas, and even in those areas that do, such clinics are available on average through only one-quarter of general practitioner practices.

There is also a dire lack of specialist obesity care provision in the National Health Service (House of Commons Health Committee, 2004). One recent estimate of the under-provision of hospital-based specialist care has stated that within the catchment area of a typical hospital serving a population of 300000 , about 53000 individuals would be obese (BMI $>30 \mathrm{~kg} / \mathrm{m}^{2}$ ), and about 3500 would be 'morbidly' obese $(\mathrm{BMI}>40)$. This estimate would mean that even if specialist obesity treatment is offered only to all patients with morbid obesity, the typical hospital clinic will require a 14-fold increase in capacity.

\section{What are the barriers to effective treatment in primary care?}

A survey of primary care staff by the National Audit Office (2001) has found a number of factors cited as being barriers to good practice, in particular: lack of information on effective interventions; lack of patient materials; lack of training; lack of time. Other potential barriers cited in a previous review include: poor access to appropriate support services; lack of motivation because of negative perceptions of overweight and obese individuals or the efficacy of treatments (Summerbell, 1998). 


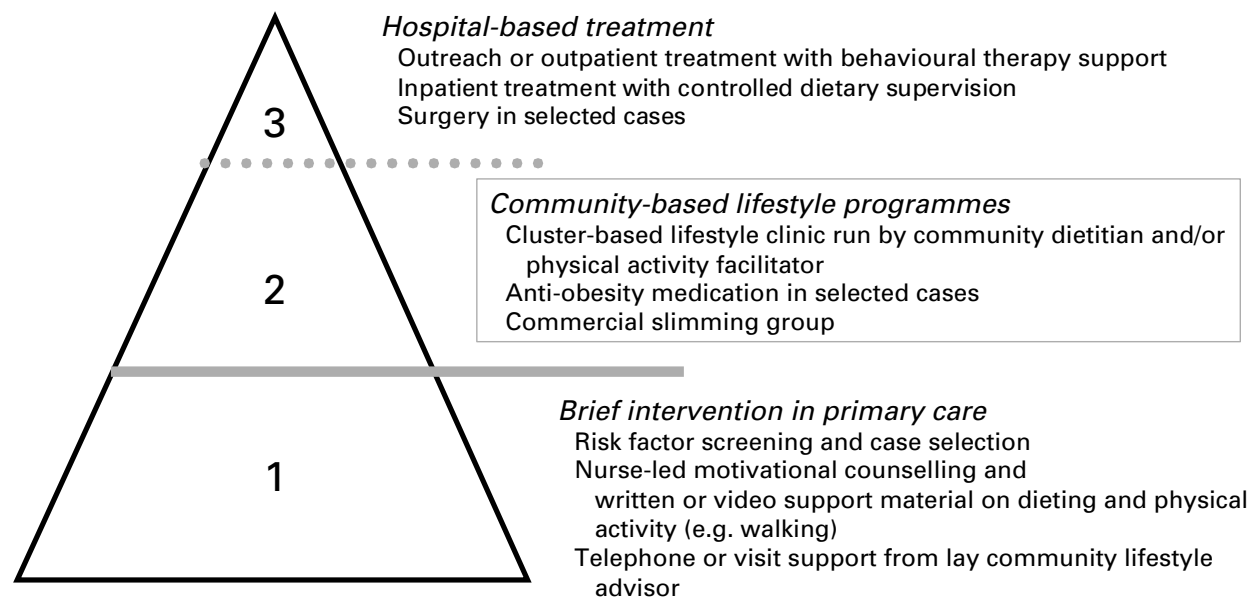

Fig. 2. The triple-tier pathway for weight management. (From Maryon-Davis, 2004.)

\section{Main barriers}

The main barriers are:

psychological complexities of cases;

high rate of relapse;

perceived lack of effective interventions;

lack of training;

lack of time;

lack of resources;

lack of onward referral options.

In short, there is a dearth of effective properly-structured well-resourced weight-management services throughout the country.

The evidence described earlier supports the following proposed changes to overcome these barriers:

agreed clinical pathway with clear guidelines on case selection, intervention and referral;

clear prescribing guidelines;

better support materials;

an expanded community dietetic service;

an expanded exercise referral service;

joined-up workforce planning;

effective engagement of the voluntary sector;

well-resourced training programmes;

funding to cover staff released for training;

an expanded hospital service;

further research to identify the most effective approaches;

clear top-down commitment with resources.

\section{Some promising developments}

There are a number of promising developments currently exploring new models of delivery in primary care in the UK.

\section{Dedicated weight-management clinics}

A service model based on dedicated practice-based weightmanagement clinics (the Counterweight Programme; Laws
\& the Counterweight Project Team, 2004) is currently being trialled in a study involving eighty general practices. The programme aims to evaluate clinics for patients aged 18-75 years run by specially-trained practice nurses using tailored evidence-based lifestyle protocols and supported by 'weight-management advisors' (dietitians). The programme will be fully audited after 2 years. Outcomes to be assessed include changes in practitioner knowledge, attitudes, perceived confidence and willingness to treat obesity, as well as changes in practice approaches to obesity management and weight-screening rates. The primary end point for the patient intervention programme will be the percentage of patients achieving $\geq 5$ and $\geq 10 \%$ weight loss. While the final conclusions of the programme will not be known for some time, the preliminary results indicate that $51 \%$ of patients have attained an appropriate level of compliance at 12 months, of whom $43 \%$ have achieved weight loss of $\geq 5 \%$. This result suggests that clinically-beneficial weight loss can be achieved in highrisk obese patients in the primary care setting.

\section{Referral to a commercial slimming organisation}

Another promising development involves referral to a commercially-run slimming group. This approach has been piloted in a small-scale study in Southern Derbyshire with encouraging results (A Avery, unpublished results). A selected sample of 107 obese patients aged 18-30 years in two general practices were reviewed by a trained study nurse and referred to a local slimming club with free vouchers for a 12 -week course. They were encouraged to attend for a further 12 weeks at their own expense. Results showed that $85 \%$ attended the course, $68 \%$ completed 12 weeks (mean percentage weight loss 6.4 (SD 2.96) \%) and $37 \%$ completed 24 weeks.

\section{The triple-tier pathway}

A third approach looks at the overall clinical pathway and service configuration, dividing it into three tiers, along similar lines to that used for smoking cessation (Fig. 2). This 'triple-tier' pathway is being proposed for deployment 
in Southwark and Lambeth (Maryon-Davis, 2004). The three tiers are:

tier 1, which involves brief verbal intervention by a general practitioner or practice nurse trained in basic motivational techniques, supported with written or video material. Patients are selected according to clinical risk of co-morbidities, and readiness to change. Additional support from specially-trained lay volunteer 'lifestyle advisors' is provided. The approach is non-pharmacological only;

tier 2, which involves referral to a community dietitian and/or leisure-based physical activity facilitator working on a cluster or locality basis, perhaps as a dedicated obesity clinic. It could also include referral to a commercial slimming group. Individual or group sessions are provided according to demand and availability. This approach could be linked to drug treatment either via the general practitioner or through a patient-group directive by another health professional;

tier 3, which includes referral to a specialist hospitalbased service, involving out-patient or in-patient dietary management and behavioural therapy, with or without exercise. It would also include possible referral for surgery (e.g. gastric banding).

The intention is for this pathway to be developed incrementally as funds allow, with some anticipated service development funding from modernisation and regeneration budgets. It would be tied, via the National Service Framework for Coronary Heart Disease (Department of Health, 2000), into the chronic disease management programme, and geared to the Quality and Outcomes Framework of the new general practitioner General Medical Services contract (Department of Health, 2003b).

\section{Conclusion: new opportunities}

The future for weight management in the primary care setting in the UK is looking brighter. A number of developments are coming together to give the service new impetus. One development is the new flexible thinking about how primary care will be configured in the future. There will be a plurality of provision, with many different models. Already there is a shift to more nurse-led clinics and services, armed with some prescribing powers and patient group directives. Also, there are more general practitioners with a special interest in obesity and more cluster or locality-based clinics. There are also moves to expand the community pharmacist's role to take on more lifestyles advice and clinical care, again including limited prescribing.

Other new opportunities include:

new general practitioner General Medical Services contract with its Quality and Outcomes Framework allowing tighter standards and rewards for compliance with regimens for diabetes, high blood pressure and CHD (Department of Health, 2003b). Future iterations of this framework could increase incentives for obesity control; new computerised primary care systems with monthly updates to a centralised national quality management and analysis system database (NHS National Programme for Information Technology, 2004);

new relationships with hospitals through payment-byresults and foundation trust status stimulating radical service redesign;

new imperatives concerning CHD and diabetes management;

new directives from the centre including the latest Priorities and Planning Framework (Department of Health, 2004a) and Public Health White Paper (Department of Health, 2004b);

a new commitment to manage performance regarding obesity control.

Above all, there is a renewed confidence that effective practical protocols and pathways for weight management and obesity treatment will soon be developed.

\section{References}

Activity Counseling Trial Research Group (2001) Effects of physical activity counseling in primary care. Journal of the American Medical Association 286, 677-687.

Banegas JR, Lopez-Garcia E, Gutierrez-Fisac JL, GuallarCastillon P \& Rodriguez-Artalejo F (2003) A simple estimate of mortality attributable to excess weight in the European Union. European Journal of Clinical Nutrition 57, 201-208.

Centre for Reviews and Dissemination (1997) The Prevention and Treatment of Obesity. Effective Health Care Bulletin, vol. 3. York: University of York.

Chief Medical Officer (2003) Health Check on the State of the Public Health: Annual Report of the Chief Medical Officer. London: Department of Health.

Chief Medical Officer (2004) At Least Five a Week-Evidence on the Impact of Physical Activity and its Relationship to Health. London: Department of Health.

Department of Health (2000) National Service Framework for Coronary Heart Disease: Modern Standards and Service Models. London: Department of Health.

Department of Health (2003a) Delivery Strategy for the Diabetes National Service Framework. London: Department of Health.

Department of Health (2003b) Delivering Investment in General Practice: Delivering the New GMS Contract. Guidance. London: Department of Health.

Department of Health (2004a) National Standards. Local Action. Health and Social Care Standards and Planning Framework 2005/06-2007/08. London: Department of Health.

Department of Health (2004b) Choosing Health-Making Healthier Choices Easier. London: Department of Health.

Diabetes Prevention Program Research Group (2002) Reduction in the incidence of type 2 diabetes with lifestyle intervention or metformin. New England Journal of Medicine 346, 393-403.

Douketis JD, Feightner JW, Attia J \& Feldman WF (1999) Periodic health examination, 1999 update. Detection, prevention and treatment of obesity. Canadian Task Force on Preventive Health Care. Canadian Medical Association Journal 160, 513-525.

Dr Foster (2003) Obesity Management in the UK-A Weighty Issue for Primary Care Organisations? London: Dr Foster Ltd.

Elley CR, Kerse N, Arroll B \& Robinson E (2003) Effectiveness of counselling patients on physical activity in general 
practice: cluster randomised controlled trial. British Medical Journal 326, 793.

Halbert, JA, Silagy CA, Finucane PM, Withers RT \& Hamdorf PA (2000) Physical activity and cardiovascular risk factors: effect of advice from an exercise specialist in Australian general practice. Medical Journal of Australia 173, 84-87.

Harvey EL, Glenny A-M, Kirk SF \& Summerbell CD (1999) A systematic review of interventions to improve health professionals' management of obesity. International Journal of Obesity and Related Metabolic Disorders 23, 1213-1222.

Harvey EL, Glenny A-M, Kirk SF \& Summerbell CD (2004) Improving health professionals' management and the organisation of care for overweight and obese people (Cochrane Review). The Cochrane Library, Issue 2. Chichester, West Sussex: John Wiley \& Sons Ltd.

Hillsdon M, Foster C, Naidoo B \& Crombie H (2004) The Effectiveness of Public Health Interventions for Increasing Physical Activity Among Adults: A Review of Reviews. Evidence Briefing. London: Health Development Agency.

House of Commons Health Committee (2004) Obesity: Third Report of Session 2003-04. vol 1. London: The Stationery Office.

Joint Health Surveys Unit (2003) Health Survey for England 2002. National Centre for Social Research. London: The Stationery Office.

Laws R \& the Counterweight Project Team (2004) A new evidence-based model for weight management in primary care: the Counterweight Programme. Journal of Human Nutrition and Dietetics 17, 191-208.

Maryon-Davis A (2003) Oral evidence given to the House of Commons Select Committee on Health. Minutes of Evidence. 6 November 2003, HC 23II, Q519. London: The Stationery Office.

Maryon-Davis A (2004) Obesity Action Plan. Working Paper for the CHD NSF Implementation Group. London: Southwark Primary Care Trust.

Moore H, Greenwood D, Gill T, Waine C, Soutter J \& Adamson AJ (2003) A cluster randomised trial to evaluate a nutrition training programme. British Journal of General Practice 53, 271-277.

Mulvihill C \& Quigley R (2003) The Management of Obesity and Overweight: An Analysis of Reviews of Diet, Physical Activity and Behavioural Approaches. Evidence Briefing. London: Health Development Agency.
National Audit Office (2001) Tackling Obesity in England: Report by the Comptroller and Auditor General. London: The Stationery Office.

National Heart, Lung, and Blood Institute (1998) Clinical Guidelines on the Identification, Evaluation, and Treatment of Overweight and Obesity in Adults. Bethesda, MD: National Institute of Health.

National Institute of Clinical Excellance (2001a) Guidance on the Use of Orlistat for the Treatment of Obesity in Adults. NICE Technology Appraisal Guidance no. 22. London: NICE.

National Institute of Clinical Excellance (2001b) Guidance on the Use of Sibutramine for the Treatment of Obesity in Adults. NICE Technology Appraisal Guidance no. 31. London: NICE.

NHS National Programme for Information Technology (2004) GMS IT - QMAS Bulletin. http://www.dh.gov.uk/assetRoot/ 04/08/42/61/04084261.pdf

Padwal R, Li SK \& Lau DC (2003) Long-term pharmacotherapy for overweight and obesity: a systematic review and metaanalysis of randomized controlled trials. International Journal of Obesity 27, 1437-1446.

Rollnick S, Mason P \& Butler C (1999) Health Behavior Change: A Guide for Practitioners. Edinburgh: Churchill Livingstone.

Scottish Intercollegiate Guidelines Network (1996) Obesity in Scotland: Integrating Prevention with Weight Management. SIGN Guideline no. 8. Edinburgh: SIGN.

Stevens W, Hillsdon M, Thorogood M \& McArdle D (1998) Cost-effectiveness of a primary care based physical activity intervention in 45-74 year old men and women: a randomised controlled trial. British Journal of Sports Medicine 32, 236-241.

Sturm R \& Wells KB (2001) Does obesity contribute as much to morbidity as poverty or smoking? Public Health 115, 229-235.

Summerbell CD (1998) Dietary treatment of obesity. In Clinical Obesity, pp. 377-408 [P Kopelman and MJ Stock, editors]. Oxford: Blackwell Scientific Press.

Swinburn B, Egger G \& Raza F (1999) Dissecting obesogenic environments: the development and application of a framework for identifying and prioritizing environmental interventions for obesity. Preventive Medicine 29, 563-570.

Wanless D (2004) Securing Good Health for the Whole Population. London: H. M. Treasury.

Wardle J (2005) Understanding the aetiology of childhood obesity: implications for treatment. Proceedings of the Nutrition Society 64, 73-79. 
https://doi.org/10.1079/PNS2004414 Published online by Cambridge University Press 